\title{
Compact C-band Rectenna for Satellite Applications
}

\author{
Alexandru Takacs ${ }^{1}$, Abderrahim Okba ${ }^{1}$ and Hervé Aubert ${ }^{1}$ \\ ${ }^{1}$ LAAS-CNRS, UPS, INPT, Toulouse, France \\ Email: aokba@laas.fr, atakacs@laas.fr, aubert@laas.fr
}

\begin{abstract}
This paper addresses the design and the characterization of a compact $\mathrm{C}$-band rectenna for satellite applications. The proposed flat dipole rectenna achieves an efficiency of $\mathbf{5 8 . 2 \%}$ at $3.25 \mathrm{GHz}$ when illuminated with an electromagnetic power density of only $33.9 \mu W / \mathrm{cm}^{2}$. The proposed rectenna is also compact; its size is $1334 \mathrm{~mm}^{2}$ that is only $16 \%$ of the square wavelength at $3.25 \mathrm{GHz}$.
\end{abstract}

Index Terms - RF and microwave energy harvesting, rectenna, wireless power transmission

\section{INTRODUCTION}

The high gain microwave antennas, mounted on the external panels of the geostationary telecommunication satellite, are fed by high RF \& microwave power (in the range of $100 \mathrm{~W}$ ). The electric field generated by the spill-over loss of these microwave antennas can reach the following highest levels (effective values): $40 \mathrm{~V} / \mathrm{m}$ in C-band, $49.5 \mathrm{~V} / \mathrm{m}$ in X-band, $106 \mathrm{~V} / \mathrm{m}$ in Ku-band, and $127 \mathrm{~V} / \mathrm{m}$ in K-band [1]. Consequently, an important amount of electromagnetic energy is available around the satellite and illuminates the antenna panels. The harvesting of the electromagnetic energy generated by the microwave antennas was identified as an interesting solution to power autonomous wireless sensors. These autonomous wireless sensors can be deployed along the surface of the panels for structure health monitoring [1]. This paper presents recent results obtained in C-band using an innovative rectenna. The proposed rectenna is composed of a flat dipole antenna enclosed by a rectangular ring and a single diode rectifier. The topology and the design methodology are detailed in Section II while the experimental results are presented in Section III.

\section{Proposed RECTENNA: TOPOLOGY AND DESIGN}

The topology of the proposed rectenna is presented in Fig. 1. It consists of a broadband flat dipole antenna (enclosed by a rectangular ring) integrated with a rectifier using a Schottky diode mounted in shunt configuration. The rectangular ring was properly dimensioned in order to lower the resonant/operating frequency of the flat antenna. Due to the use of the outer rectangular ring the size of the flat dipole anten$\mathrm{na} /$ rectenna is only of $46 \mathrm{~mm} \times 29 \mathrm{~mm}$. The rectifier is composed of a HSMS2850 Schottky diode from Avago, a shunt capacitor $(100 \mathrm{pF})$ and a resistive load. The diode is mounted on the top of the rectenna (as illustrated in Fig. 1) while the shunt capacitor and load are connected on the back-side of the rectenna. Two metallic via-holes are used in order to connect the diode (mounted on the top of the PCB) with the shunt capacitor (located of the bottom of the PCB). The position of the shunt capacitor is critical and impacts the impedance matching between the antenna and the rectifier. Simulations and experiments (not shown here) were performed and the optimal distance (between the shunt capacitor and the diode) is $1.3 \mathrm{~cm}$. Elliptical holes, properly dimensioned (outer radius: $7.5 \mathrm{~mm}$, inner radius: $6 \mathrm{~mm}$ ) are inserted on the flat dipole in order to reject the high order harmonics generated by the rectifier.

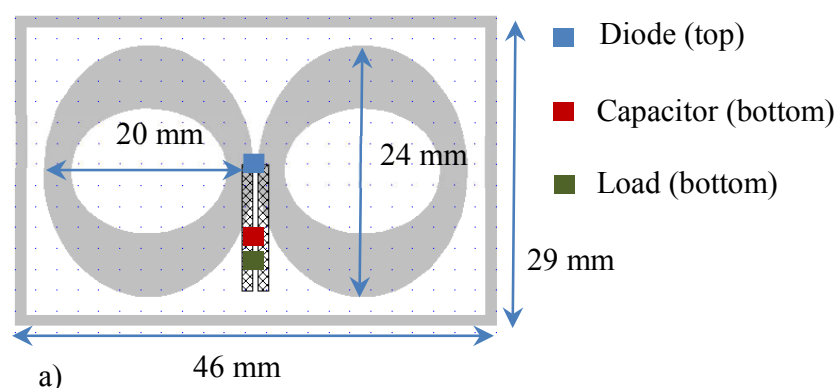

b)

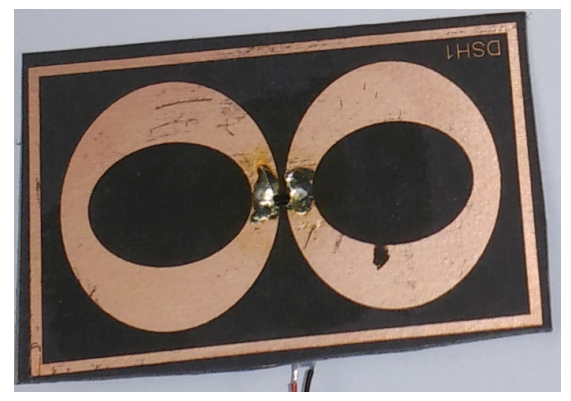

Fig. 1. Flat Dipole Rectenna (FDR): (a) the layout and the main dimensions and (b) photo of the manufactured rectenna.

The Flat Dipole Rectenna (FDR) was designed to operate at 3.4 GHz. At this frequency the satellite antenna panel is illuminated (due to the spill-over losses of the C-band broadcasting antenna) by an electric field: $2 \mathrm{~V} / \mathrm{m}<$ E-field $<15 \mathrm{~V} / \mathrm{m}(1$ $\mu \mathrm{W} / \mathrm{cm}^{2}<$ electromagnetic power density $<59.7 \mu \mathrm{W} / \mathrm{cm}^{2}$ ) [2].

\section{SIMULATION AND EXPERIMENTAL RESULTS}

The Flat Dipole Antenna (FDA) was designed from intensive electromagnetic simulations (method of moments, Altair 
FEKO). The highest gain of the FDA is of $2 \mathrm{dBi}$ and can be increased when a metallic reflector is properly positioned behind the antenna. The simulated gain (along the z-axis) of the FDA with the reflector (size: $157 \mathrm{~mm}$ x $92 \mathrm{~mm}$ ) positioned at $27 \mathrm{~mm}$ behind the antenna is displayed in Fig. 2 as a function of the frequency. The simulated input impedance is shown in Fig. 3. In order to maximize the performances of the FDR a complex conjugate impedance matching technique (between the rectifier and the FDA) was adopted. The input impedance of the rectifier was initially estimated by using a close-form expression [3]-[4]. At this stage, the impact of the vias-holes, coplanar stripline (on the bottom side) and the mounting position of the RF shunt capacitor are neglected. The position of the shunt capacitor was tuned in order to maximize the FDR performances.

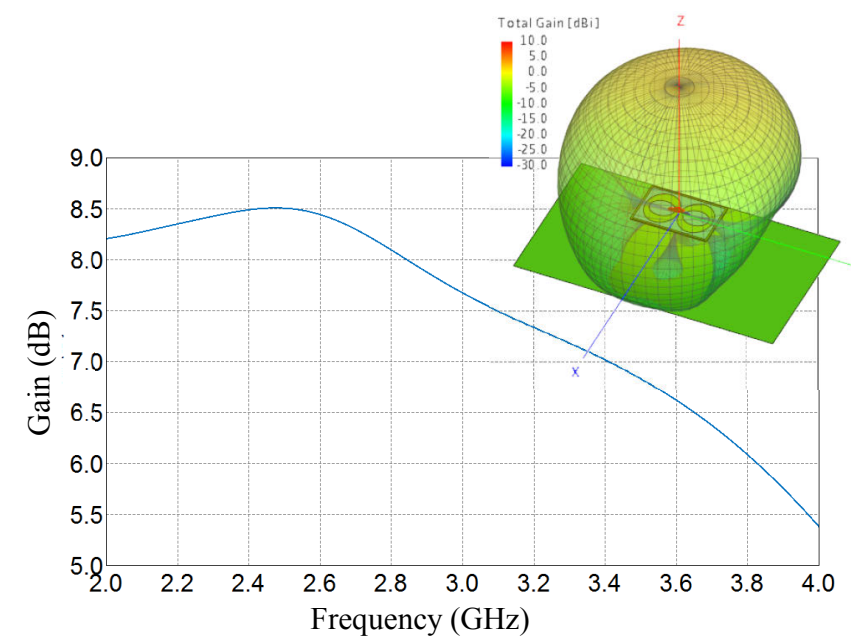

Fig. 2. Simulated (FEKO) maximum gain of FDA as a function of the frequency. The inset shows the $3 \mathrm{D}$ (gain) radiation pattern at $3.4 \mathrm{GHz}$.

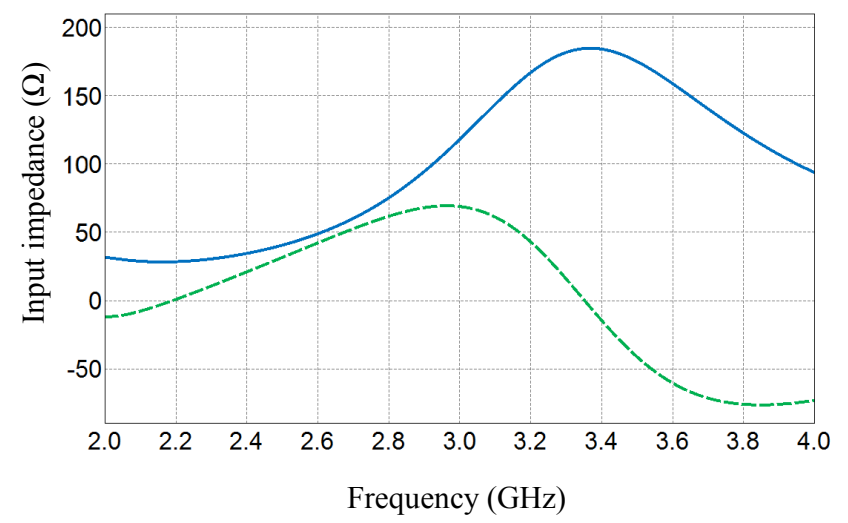

Fig. 3. Simulated (FEKO) input impedance of FDA as a function of the frequency (continuous blue curve: real part; dotted green curve: imaginary part).

The experimental setup positioned in an anechoic chamber (to prevent any interferences or undesirable multipath effects) shown in Fig. 4 was used to characterize the rectenna. A microwave signal generated from the Anritsu MG3694B generator is injected at the input of a transmitting (Tx) horn antenna through a coaxial cable. The horn antenna illuminates the rectenna under test, positioned in the far-field region of the Tx antenna, with a linearly-polarized E-field. An automatic acquisition routine is implemented in Labview software from National Instruments to speed-up the acquisition process. The harvested DC voltage is then measured by using a DC multimeter. The DC power can be derived from the measured DC voltage, as long as the load is known. The RF-to-DC conversion efficiency $\eta$ (in \%) of the rectenna can be computed by using the following expression [5]:

$$
\eta=\frac{P_{D C}}{P_{R F}} \cdot 100=\frac{P_{D C}}{S \cdot A_{e f f}} \cdot 100=\frac{4 \cdot \pi \cdot P_{D C}}{S \cdot G_{R} \cdot \lambda^{2}} \cdot 100
$$

where $P_{D C}$ is the harvested DC power, $S$ is the incident electromagnetic power density, $A_{\text {eff }}$ is the antenna effective area, $G_{R}$ is the gain of the (rectenna's) antenna and $\lambda$ is the freespace wavelength of the illuminating electromagnetic wave at the operating frequency. The electromagnetic power density $S$ can be computed as a function of the E-field effective value $E$ $(\mathrm{V} / \mathrm{m})$ on the antenna surface. This value is derived from microwave power $P_{t}$ injected to the input port of the transmitting horn antenna (gain $G_{t}$ ) positioned at a distance $d$ from the rectenna, as follows:

$$
S=\frac{E^{2}}{120 \cdot \pi}=\frac{30 \cdot P_{t} \cdot G_{t}}{d^{2} \cdot 120 \cdot \pi}
$$

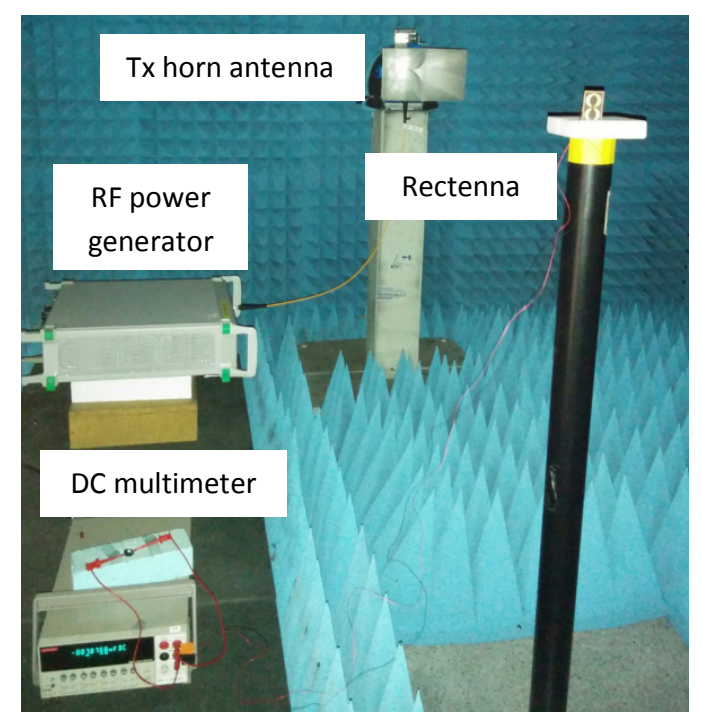

Fig. 4. Experimental setup used to characterize the manufactured rectenna.

A RF power density of $33.9 \mu \mathrm{W} / \mathrm{cm}^{2}$ (that roughly corresponds to the average RF power density generated by the spillover losses of the C-band broadcasting antenna at $3.4 \mathrm{GHz}$ ) was generated by adopting the following configuration: $P_{t}=27$ $\mathrm{dBm}$ (the coaxial cable and connector insertion losses of $1 \mathrm{~dB}$ was removed from $\left.P_{t}\right), G_{t}=11.87 \mathrm{dBi}$ and $d=1.20 \mathrm{~m}$.

The following approach was adopted in order to characterize our rectenna: (i) a frequency sweep was conducted for a selected load $(1.5 \mathrm{k} \Omega$ ) in order to find the optimal operating 
frequency (at this frequency the harvested DC power and the efficiency are maximized on the given load); (ii) the optimal load and then the maximum harvested DC power and the maximum efficiency were determined at this optimal operating frequency. The measurements were performed without and with a metallic plate, positioned at $2.7 \mathrm{~cm}$ behind of the rectenna. This metallic plate simulates the presence of the metallic part of the satellite antenna panels. The obtained results (measured DC voltage and DC power), as a function of the frequency, are depicted in Fig. 5 and Fig. 6, respectively.

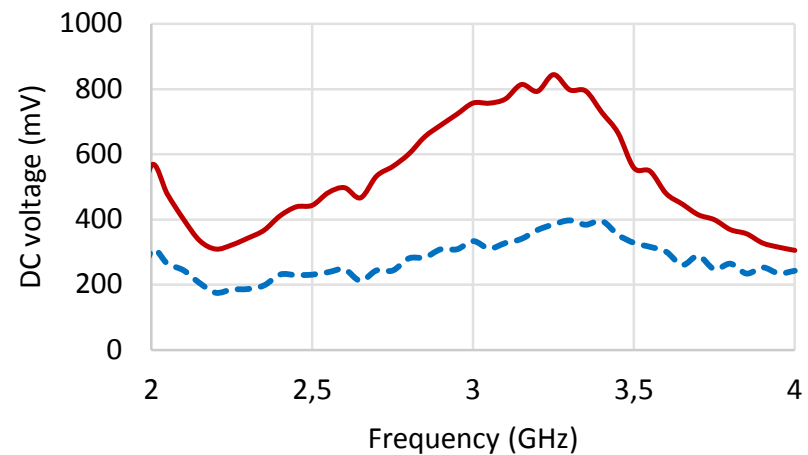

Fig.5. Measured DC voltage $(\mathrm{mV})$ for the FDR (incident power density: $\mathrm{S}=33.9 \mu \mathrm{W} / \mathrm{cm}^{2}$, load $1.5 \mathrm{k} \Omega$ ) as function of the frequency: dotted blue curve (without any reflector plane), continuous red curve (with a metallic reflector positioned at $2.7 \mathrm{~cm}$ behind the rectenna)

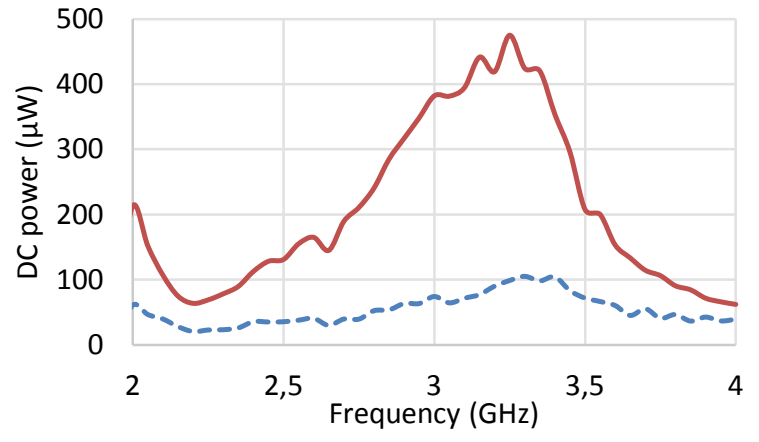

Fig.6. $\quad$ Measured DC power $(\mu \mathrm{W})$ for the FDR (incident power density: $\mathrm{S}=33.9 \mu \mathrm{W} / \mathrm{cm}^{2}$, load $1.5 \mathrm{k} \Omega$ ) as function of the frequency: dotted blue curve (without any reflector plane), continuous red curve (with a metallic reflector positioned at $2.7 \mathrm{~cm}$ behind the rectenna)

As shown in Fig. 6, a maximum DC power of $475 \mu \mathrm{W}$ was obtained at $3.25 \mathrm{GHz}$ with a load of $1.5 \mathrm{k} \Omega$ when the reflector is positioned at $2.7 \mathrm{~cm}$ behind the rectenna. Due to the adopted antenna topology and matching technique, FDR exhibits also a wideband behavior: the half (DC-harvested) power frequency bandwidth is approximately of $20 \%(0.65 \mathrm{GHz})$. The optimal operating frequency is of $3.25 \mathrm{GHz}$ instead of the targeted $3.4 \mathrm{GHz}$ (that is a frequency shift of $4.5 \%$ ), and it may be mainly caused by: (i) the approximation made when using the close-form expression for estimating the input impedance of the rectifier, and (ii) the technological inaccuracies when manufacturing and the assembling the FDR. This fre- quency shift (of the maximum efficiency operating point) of $4.5 \%$ is not so critical because the half (DC harvested) power frequency bandwidth is $20 \%$.

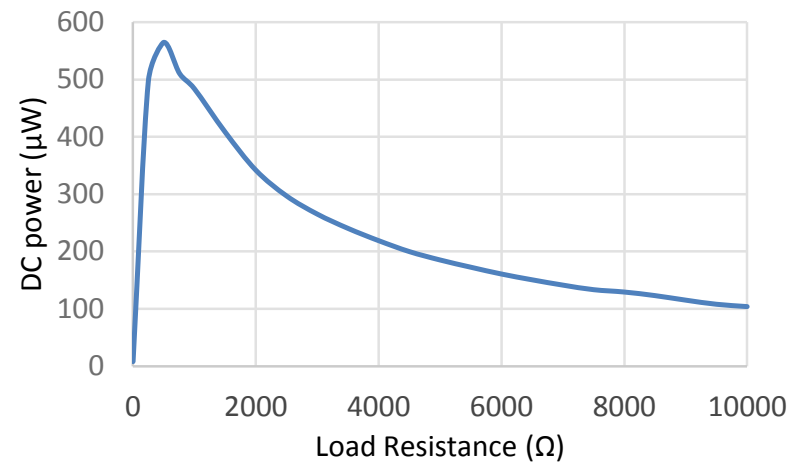

Fig.7. Measured harvested DC power as function of the load resistance for the FDR with a reflector positioned at $2.7 \mathrm{~cm}$ behind the rectenna (incident power density: $\mathrm{S}=33.9 \mu \mathrm{W} / \mathrm{cm}^{2}$, frequency: $\mathrm{f}=3.25 \mathrm{GHz}$ )

The optimal purely resistive load and the maximum efficiency were experimentally determined for FDR at $3.25 \mathrm{GHz}$. As shown in Fig.7 and Fig.8, the optimal load is of $500 \Omega$. For this load, the harvested DC power and efficiency are of 565 $\mu \mathrm{W}$ and $58.2 \%$, respectively. We note that the efficiencies reported in Fig. 8 are undervalued as the simulated gain $G_{R}$ (=7.26 dBi, see Fig. 2) is adopted here for deriving the efficiencies.

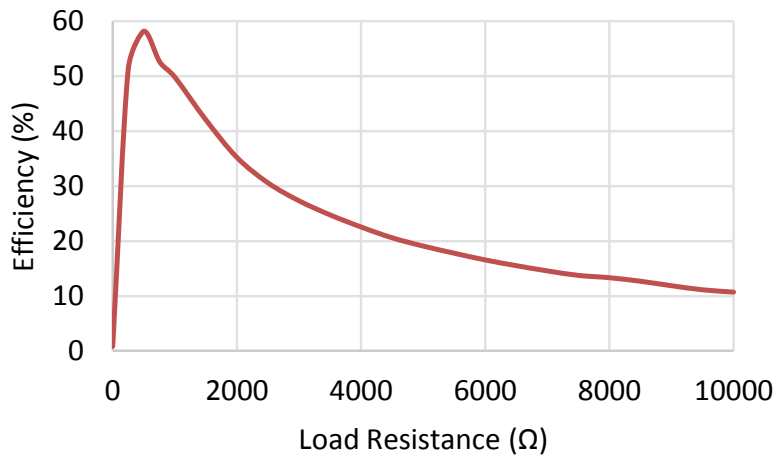

Fig. 8 Efficiency (\%) as function of the load resistance for the FDR with a reflector positioned at $2.7 \mathrm{~cm}$ behind the rectenna (incident power density: $\mathrm{S}=33.9 \mu \mathrm{W} / \mathrm{cm}^{2}$, frequency: $\mathrm{f}=3.25 \mathrm{GHz}$ )

In Table I, the rectenna performances are compared with state-of-art designs operating at (almost) the same frequencies. The rectenna proposed in this paper was designed for energy harvesting applications (on board of broadcasting geostationary satellites) in C-band and operates efficiently for low value of the RF power densities. 
Table I. Benchmark Results

\begin{tabular}{|c|c|c|c|c|c|}
\hline Refs. & $\begin{array}{c}\text { Operating } \\
\text { frequency } \\
\mathrm{f}_{0}(\mathrm{GHz})\end{array}$ & $\begin{array}{l}\text { Power density } \\
\left(\mu \mathrm{W} / \mathrm{cm}^{2}\right) \text { or } \\
\text { received RF } \\
\text { power }(\mathrm{dBm})\end{array}$ & $\begin{array}{c}\text { Har- } \\
\text { vested } \\
\text { DC } \\
\text { power } \\
(\mathrm{mW})\end{array}$ & $\begin{array}{c}\text { Rectenna } \\
\text { efficiency } \\
(\%)\end{array}$ & $\begin{array}{c}\text { Antenna } \\
\text { Surface } \\
\text { ( } \lambda_{0} \text { is the } \\
\text { wavelength } \\
\left.\text { at } \mathrm{f}_{0}\right)\end{array}$ \\
\hline$[6]$ & 2.45 & $525 \mu \mathrm{W} / \mathrm{cm}^{2}$ & 4.97 & 63 & $\begin{array}{c}10 \times 11 \mathrm{~cm}^{2} \\
\left(0.73^{*} \lambda_{0}{ }^{2}\right)\end{array}$ \\
\hline [7] & 2.45 & $13 \mathrm{dBm}$ & NR & 72.5 & $\begin{array}{c}13.5 \times 9.3 \\
\mathrm{~cm}^{2} \\
\left(0.83^{*} \lambda_{0}{ }^{2}\right)\end{array}$ \\
\hline [8] & 2.4 & $22 \mathrm{dBm}$ & 130 & 82.3 & $\begin{array}{c}10 \times 10 \mathrm{~cm}^{2} \\
\left(0.64 * \lambda_{0}{ }^{2}\right)\end{array}$ \\
\hline [3] & 5.8 & $8.77 \mathrm{~mW} / \mathrm{cm}^{2}$ & 49.1 & 82.7 & NR \\
\hline [9] & 5.8 & $12 \mathrm{~mW} / \mathrm{cm}^{2}$ & NR & 76 & NR \\
\hline $\begin{array}{l}\text { This } \\
\text { work }\end{array}$ & 3.25 & $\begin{array}{c}33.9 \mu \mathrm{W} / \mathrm{cm}^{2} \\
(-0.1 \mathrm{dBm})\end{array}$ & 0.57 & 58.2 & $\begin{array}{c}4.6 \times 2.9 \mathrm{~cm}^{2} \\
\left(0.16^{*} \lambda_{0}{ }^{2}\right)\end{array}$ \\
\hline
\end{tabular}

NR: Not Reported

In order to quantify the electromagnetic energy illuminating the rectenna and to compute the RF-to-DC conversion efficiency two approaches can be used. The electromagnetic energy can be expressed in terms of power densities (this work, [3], [6], [9]) or alternatively in terms of the estimated RF power at the input of the rectifier [7]-[8]. We note that most of the published designs (see, e.g., [3][9]) covering (the upper) C-band were designed for wireless power transmission applications at $5.8 \mathrm{GHz}$ and optimized for very high levels of incident RF powers $\left(8.77 \mathrm{~mW} / \mathrm{cm}^{2}\right.$ or $\left.12 \mathrm{~mW} / \mathrm{cm}^{2}\right)$. Compared with the reported designs operating in the ISM $2.45 \mathrm{GHz}$ band, our rectenna is significantly more compact and operates very efficiently when illuminated with much lower electromagnetic power density $\left(34 \mu \mathrm{W} / \mathrm{cm}^{2}\right.$ for this work as compared with $525 \mu \mathrm{W} / \mathrm{cm}^{2}$ in [6]). The estimated RF power at the input of the rectifier is also significantly lower $(-0.1 \mathrm{dBm}$ for this work as compared with $13 \mathrm{dBm}$ in [7] or $22 \mathrm{dBm}$ in [8]).

\section{CONCLUSION}

An innovative C-band rectenna using a compact flat dipole antenna was proposed. This rectenna operates very efficiently for low level of RF power densities. The maximum efficiency of $58.2 \%$ was obtained for the incident RF power density of $33.9 \mu \mathrm{W} / \mathrm{cm}^{2}$. The rectenna size is only $16 \%$ of the square wavelength at $3.25 \mathrm{GHz}$.

\section{ACKNOWLEDGMENT}

The authors wish to acknowledge Gaël Loubet for his valuable help during the rectenna characterization and French Space Agency (CNES) for partially supporting this research in the frame of several past R\&T Grants.

\section{REFERENCES}

[1] A. Takacs, H. Aubert, S. Fredon, L. Despoisse, H. Blondeaux, "Microwave power harvesting for satellite health monitoring", IEEE Trans. Microw. Theory Techn., Vol.: 62, Issue: 4, pp. 1090 - 1098, April 2014.

[2] Study of various micro-sources for energy generation and storage on board satellites, Report for the French Space Agency, Grant $\mathrm{n}^{\circ}$ 115052/201, 2011-2012 (in french)

[3] Y.-H. Suh and K. Chang, "A high-efficiency dual-frequency rectenna for 2.45- and 5.8-GHz wireless power transmission," IEEE Trans. Microw. Theory Techn., vol. 50, no. 7, pp. 1784-1789, July 2002.

[4] J. Guo, X. Zhu, "An Improved Analytical Model for RF-DC Conversion Efficiency in Microwave Rectifiers", IEEE MTT-S International Conference, Montreal, QC, Canada, 17-22, June 2012.

[5] Z. Popovic; E.A. Falkenstein, D. Costinett, R. Zane, Low-Power FarField Wireless Powering for Wireless Sensors, Proceedings of the IEEE, Vol. 101, No. 6, pp.1397-1407, June 2013.

[6] Z, Harouni, L, Cirio, L, Osman, A, Gharsallah, and O, Picon, "A Dual Circularly Polarized 2,45-GHz Rectenna for Wireless Power Transmission," IEEE Antennas Wireless Propagat. Lett., Vol. 10, pp. 306-309, 2011

[7] N. Mei-Juan, "A compact $2.45 \mathrm{GHz}$ Broadband Rectenna Using Grounded Coplanar Waveguide." IEEE Antennas Wireless Propagat. Lett., vol. 14, pp. 986 - 989, January 2015.

[8] J. H. Chou, D. B. Lin, K. L. Weng, and H. J. Li, "All Polarization Receiving Rectenna With Harmonic Rejection Property for Wireless Power Transmission," IEEE Trans. Antennas Propagat., vol. 62, no. 10, pp. 5242-5249, Oct. 2014.

[9] Y.-J. Ren and K. Chang, 5.8-GHz Circularly Polarized Dual-Diode Rectenna and Rectenna Array for Microwave Power Transmission, IEEE Trans. Microw. Theory Techn., Vol.54, Issue 4, pp 1495-1502, June 2006 